\title{
ANALISIS LAPORAN AKUNTABILITAS KINERJA PADA DINAS PEMBERDAYAAN MASYARAKAT DAN DESA KABUPATEN MINAHASA SELATAN
}

\author{
Anita Carolina Tambarici ${ }^{1}$, Lintje Kalangi ${ }^{2}$, Dhullo Afandi ${ }^{3}$ \\ 1,2,3 Jurusan Akuntansi, Fakultas Ekonomi dan Bisnis, Universitas Sam Ratulangi, Jl. Kampus Bahu, Manado \\ 95115, Indonesia
}

Email : anitacaroline17@gmail.com

\begin{abstract}
The government must periodically communicate the achievement of the organization's strategic goals and objectives to stakeholders as outlined in the Government Institutional Performance Accountability Report (LAKIP). However, these efforts do not seem to be fully supported by the institutions and bureaucracy in question. This can be evidenced by the finding of more and more cases that harm the country's finances up to trillions of rupiah. These cases are mostly in the form of Corruption, Collusion and Nepotism (KKN) practices carried out by certain elements in institutions and bureaucracy that are owned by the government. In addition, the problems that are often found in LAKIP are frequent points of realization the budget and its achievements are not aligned where the funds or budget realized in an activity are not clear about the details and details so that LAKIP is often not in line with the Strategic Plan prepared by the government. This study aims to analyze the adequacy of the Performance Accountability Report of Government Agencies (LAKIP) of South Minahasa DPMD. The analysis method used in this study is descriptive method with the Balanced Scorecard approach. LAKIP The Community and Village Empowerment Office of South Minahasa Regency is in accordance with the perspective of the Balanced Scorecard that has been implemented. Performance achievements that have been good and have been accomplished by the South Minahasa District DPMD need to be maintained and developed again.
\end{abstract}

Keywords : Accountability, Perfomance, Report, Balanced Scoredcard, DPMD

\section{PENDAHULUAN}

Secara berkala pemerintah wajib menyampaikan pencapaian tujuan dan sasaran strategis organisasi kepada para stakeholders melalui LAKIP. Tetapi upaya-upaya tersebut belum didukung penuh oleh institusi yang dimaksud. Perihal tersebut terbukti melalui ditemukannya kasus-kasus yang membuat keuangan negara dirugikan. Kasus-kasus tersebut seperti praktik-praktik KKN yang dilakukan oleh oknum-oknum tertentu dalam institusi dan birokrasi yang dimiliki oleh pemerintah.

Selain itu permasalahan yang sering di temukan dalam LAKIP adalah sering ditemukannya poin-poin realisasi anggaran dan pencapaiannya tidak selaras dimana dana atau anggaran yang direalisasikan dalam sebuah kegiatan tidak jelas keterangan dan rinciannya sehingga seringkali LAKIP yang di buat terkadang tidak selaras dengan Renstra yang disusun oleh pemerintah. Berdasarkan uraian inilah maka perlu dilakukan analisis terhadap LAKIP Dinas Pemberdayaan Masyarakat dan Desa Kabupaten Minahasa Selatan dengan menggunakan pendekatan Balanced Scorecard. Berdasarkan uraian latar belakang penelitian maka peneliti merumuskan masalah dalam penelitian ini adalah Apakah LAKIP pada Dinas Pemberdayaan Masyarakat dan Desa Kabupaten Minahasa Selatan telah memadai?. Selain itu tujuan penelitian ini adalah untuk menganalisis memadai tidaknya Laporan Akuntabilitas Kinerja Instansi Pemerintah (LAKIP) DPMD Minahasa Selatan. 


\section{TINJAUAN PUSTAKA}

Konsep Akuntansi. Wild, Shaw dan Chiappetta (2014:3) menyatakan akuntansi adalah ilmu yang mempelajari tentang pencatatan, pengidentifikasian dalam sistem informasi yang berguna dalam penyampaian informasi yang relevan dalam organisasi perusahaan. Thomas (2013:1) menyatakan akuntansi merupakan seni mengumpul, mengidentifikasi, mengklasifikasi, mencatat transaksi keuangan, untuk menghasilkan informasi laporan keuangan yang bisa digunakan oleh pihak yang berkepentingan.

Konsep Akuntansi Sektor Publik. Halim (2014: 97) menyatakan akuntansi sektor publik adalah kegiatan jasa untuk menyediakan informasi keuangan dari instansi pemerintah yang berguna sebagai tolak ukur dalam mengambil keputusan ekonomi dari berbagai pihak yang berkepentingan atas berbagai alternatif tindakan. Menurut Sujarweni (2015:1) akuntansi sektor publik merupakan kegiatan jasa yang terdiri dari pencatatan, pengklasifikasian, dan pelaporan transaksi ekonomi sehingga menghasilkan informasi keuangan yang digunakan oleh pihak tertentu untuk mengambil keputusan, dan penerapannya pada pengelolaan dana publik.

Konsep Akuntabilitas. Menurut Mardiasmo (2011:3) akuntabilitas adalah kewajiban pemegang amanah dalam memberi pertanggungjawaban, penyajian, pelaporan, dan pengungkapan setiap kegiatan yang menjadi tanggung jawabnya kepada pemberi amanah yang mempuyai kewenangan untuk meminta pertanggungjawaban.

Prinsip-prinsip Akuntabilitas. Prinsip-prinsip akuntabilitas dalam lingkungan internal pemerintah yang harus diperhatikan, dikutip LAN dan BPKP (Badan Pengawas Keuangan dan Pembangunan) (2000:43) yaitu:

1. Untuk menjalankan pengelolaan pelaksanaan misi agar akuntabel, pimpinan dan pegawai instansi harus memiliki komitmen.

2. Harus berupa sebuah sistem yang sesuai dengan UU yang berlaku dan bisa menjamin penggunaan sumber secara konsisten.

3. Menunjukkan peningkatan terhadap sasaran dan tujuan yang disetujui.

4. Berkontribusi dalam melakukan visi dan misi serta hasil dan manfaat yang didapatkan.

5. Jujur, obyektif, transparan, dan inovatif sebagai pemuka perubahan manajemen instansi pemerintah yang berbentuk pembauran metode, teknik pengukuran kinerja dan penyusunan LAKIP.

Konsep Kinerja. Menurut Sujarweni (2015:107) kinerja ialah hasil kerja yang tercapai dalam melaksanakan kegiatan yang bertujuan untuk meraih tujuan, sasaran, visi dan misi organisasi. Sistem pengukuran kinerja sektor publik memiliki tujuan untuk mendukung manajer sektor publik dalam melakukan penilaian pencapaian strategi melalui alat ukur finansial dan nonfinansial. Menurut Santoso (2013) pengukuran kinerja sektor publik meliputi berbagai aspek:

1. Kelompok masukan merupakan hal-hal yang diperlukan supaya bisa melaksanakan kegiatan sehingga mendapatkan keluaran.

2. Kelompok proses merupakan tingkatan kegiatan dari sisi ketepatan ataupun tingkat penyelesaiannya.

3. Kelompok keluaran merupakan suatu hal yang bisa tercapai dari suatu kegiatan.

4. Kelompok hasil merupakan hal yang berkaitan dengan tujuan akhir dari kegiatan.

5. Kelompok dampak merupakan efek yang timbul baik dari sisi positif maupun negatif.

Laporan Akuntabilitas Kinerja Instansi Pemerintah (LAKIP). LAKIP adalah laporan yang didalamnya berisi tentang akuntabilitas dan kinerja dari instansi pemerintah atau satuan kerja perangkat daerah (SKPD) untuk pemerintah daerah tingkat kabupaten/kota. SKPD merupakan instansi kerja pemerintah yang memiliki hak dan tanggung jawab mengolah sendiri administrasi maupun keuangan. Lakip disusun sesuai dengan siklus 
anggaran berjalan yaitu 1 tahun, yang berisi semua laporan untuk memberikan perbandingan perencanaan dan hasil untuk menyusun kegiatan (Santoso, 2013).

Konsep Balanced Scorecard. Balanced Scorecard adalah pengukuran kinerja organisasi berdasarkan aspek finansial dan aspek nonfinansial. Balanced Scorecard dianggap sesuai dalam organisasi sektor publik dikarenakan Balanced Scorecard bukan hanya menekankan pada aspek kuantitatif-finansial, tapi juga aspek kualitatif dan nonfinansial. Hal ini searah dengan organisasi sektor publik yang menempatkan laba bukan sebagai ukuran kinerja utama, tetapi pelayanan yang cenderung bersifat nonkeuangan. (Kaplan dan Norton, 2011). Capaian kinerja bisa dilihat melalui perhitungan indeks kinerja, oleh karena itu indeks capaian terhadap kinerja organisasi/lembaga harus ditentukan terlebih dahulu. Indeks capaian kinerja berdasarkan indeks kinerja dalam format LAKIP:

\begin{tabular}{lllll}
\hline $0 \%$ & - & $55 \%$ & dikategorikan & Buruk \\
$56 \%$ & - & $70 \%$ & dikategorikan & Sedang \\
$71 \%$ & - & $85 \%$ & dikategorikan & Baik \\
$86 \%$ & - & $>100 \%$ & dikategorikan & Sangat Baik \\
\hline
\end{tabular}

Sumber : Sujarweni (2015)

Empat perspektif $B S C$ yang digunakan dalam penelitian ini adalah : (1) perspektif finansial; (2) perspektif customer and stakeholders; (3) perspektif internal business process; dan (4) perspektif employees and organization capacitys.

Penelitian Terdahulu. Huda dan Riharjo (2013). Analisis dan evaluasi kinerja Dinas Kebudayaan dan Pariwisata Provinsi Jawa Timur. Hasil penelitian menjelaskan bahwa Dinas Kebudayaan dan Pariwisata Provinsi Jawa Timur mampu meningkatkan kemampuan pengelolaan nilai dan keragaman budaya, mampu memperbaiki perlindungan, pengembangan dan pemanfaatan aset budaya sehingga bisa berfungsi optimal. Fairus dan Andri (2014). Perencanaan Kinerja Tahunan Melalui Penilaian Evaluasi Lakip. Penelitian ini menyatakan bahwa perencanaan kinerja tahunan melalui penilaian evaluasi Lakip 2012 di Kabupaten Siak adalah baik. Proses perencanaan kinerja dinilai melalui evaluasi Lakip 2012 sudah terlaksana dengan baik.

\section{METODE PENELITIAN}

Jenis Penelitian. Jenis penelitian yang digunakan yaitu deskriptif kualitatif yaitu bermaksud menyelidiki keadaan atau kondisi yang terjadi di Dinas Pemberdayaan Masyarakat dan Desa Kabupaten Minahasa Selatan mengenai laporan akuntabiltas kinerja dan hasilnya dapat dideskripsikan dalam laporan penelitian.

Tempat dan Waktu Penelitian. Penelitian ini dilakukan di Dinas Pemberdayaan Masyarakat dan Desa Kabupaten Minahasa Selatan. Waktu penelitian dari bulan Februari sampai dengan bulan April 2018.

Jenis, Sumber dan Metode Pengumpulan Data. Jenis data yang penulis gunakan adalah data kualitatif. Data kualitatif adalah data yang di sajikan secara deskriptif atau data yang berbentuk uraian, sedangkan data kuantitatif adalah data yang dapat diukur dalam suatu skala numerik (Kuncoro, 2011:145). Sumber data yang digunakan yaitu sumber primer dan sekunder. Sumber primer yang digunakan yaitu data yang diambil langsung pada Dinas Pemberdayaan Masyarakat dan Desa Kabupaten Minahasa Selatan. Sedangkan data sekunder yang dipakai adalah data dari lembaga pengumpul data.

Teknik yang dipakai dalam pengumpulan data-data penelitian ini adalah: (1) wawancara; (2) dokumentasi; dan (3) media elektronik. 
Metode dan Proses Analisis. Metode yang dipakai dalam menganalisis ialah metode analisis deskriptif yaitu metode yang dipakai dalam menganalisis hasil penelitian tapi tidak menggunakannya dalam membuat kesimpulan yang lebih luas (Sugiyono 2014:21). Analisis deskriptif yang dimaksud yaitu menggunakan pendekatan Balanced Scorecard untuk mengukur Laporan Akuntabilitas Kinerja Dinas Pemberdayaan Masyarakat dan Desa Kabupaten Minahasa Selatan berdasarkan empat perspektif Balanced Scorecard: (1) perspektif finansial; (2) perspektif customer and stakeholders; (3) perspektif internal business process; dan (4) perspektif employees and organization capacitys.

\section{HASIL ANALISIS DAN PEMBAHASAN}

\subsection{Hasil Analisis}

Tabel 1. Capaian Kinerja DPMD Kabupaten Minahasa Selatan

\begin{tabular}{|c|c|c|c|c|c|c|c|c|}
\hline \multirow[t]{2}{*}{ No } & \multirow[t]{2}{*}{ Sasaran } & \multirow[t]{2}{*}{$\begin{array}{l}\text { Indikator } \\
\text { Sasaran }\end{array}$} & \multirow[t]{2}{*}{$\begin{array}{l}\text { Program/ } \\
\text { Kegiatan }\end{array}$} & \multirow[t]{2}{*}{$\begin{array}{l}\text { Indikator } \\
\text { Kinerja } \\
\text { Program dan } \\
\text { Kegiatan }\end{array}$} & \multicolumn{2}{|c|}{$\begin{array}{c}\text { Capaian } \\
\text { Kinerja } \\
\text { Program dan } \\
\text { Kerangka } \\
\text { Pendanaan } \\
\end{array}$} & \multicolumn{2}{|l|}{$\begin{array}{l}\text { Realisasi } \\
\text { Keuangan }\end{array}$} \\
\hline & & & & & Target & Rp. & Rp. & $\%$ \\
\hline \multirow[t]{9}{*}{1} & & & 2 & 3 & 5 & 6 & 7 & 8 \\
\hline & & & $\begin{array}{l}\text { URUSAN } \\
\text { WAJIB }\end{array}$ & & & & & \\
\hline & & & $\begin{array}{c}\text { DINAS } \\
\text { PEMBERDAYAAN } \\
\text { MASYARAKAT } \\
\text { DAN DESA }\end{array}$ & & \multicolumn{2}{|c|}{2.628 .200 .154} & 2.478.473.839 & 94.3 \\
\hline & $\begin{array}{l}\text { Terlaksananya } \\
\text { penatausahaan } \\
\text { administrasi } \\
\text { keuangan } \\
\end{array}$ & $\begin{array}{c}\text { Tersedianya } \\
\text { anggaran } \\
\text { administrasi } \\
\text { keuangan } \\
\end{array}$ & $\begin{array}{l}\text { Penyediaan jasa } \\
\text { administrasi } \\
\text { keuangan }\end{array}$ & $\begin{array}{l}\text { Lancarnya } \\
\text { pelaksanaan } \\
\text { tugas-tugas }\end{array}$ & $\begin{array}{c}12 \\
\text { bulan }\end{array}$ & 141.000 .000 & 141.000 .000 & 100 \\
\hline & & $\begin{array}{c}\text { Tersedianya } \\
\text { Alat Tulis } \\
\text { Kantor }\end{array}$ & $\begin{array}{l}\text { Penyediaan alat tulis } \\
\text { kantor }\end{array}$ & $\begin{array}{l}\text { Lancarnya } \\
\text { pelaksanaan } \\
\text { tugas-tugas }\end{array}$ & $\begin{array}{c}12 \\
\text { bulan }\end{array}$ & 20.226 .400 & 20.000 .000 & 98.88 \\
\hline & & & $\begin{array}{l}\text { Penyelenggaraan } \\
\text { Dimensi Informasi } \\
\text { bagi Masyarakat }\end{array}$ & $\begin{array}{c}\text { Terlaksananya } \\
\text { terlaksananya } \\
\text { Diseminasi } \\
\text { Informasi } \\
\text { Bagi } \\
\text { Masyarakat }\end{array}$ & $1 \mathrm{keg}$ & 245.000 .000 & 234.500 .000 & 95.71 \\
\hline & & & $\begin{array}{c}\text { Pembinaan } \\
\text { Kelompok } \\
\text { Masyarakat } \\
\text { Pembangunan Desa }\end{array}$ & $\begin{array}{c}\text { Terlaksananya } \\
\text { Lomba Desa } \\
\text { dan } \\
\text { Kelurahan } \\
\text { Tingkat } \\
\text { Kabupaten } \\
\end{array}$ & $\begin{array}{r}167 \\
\text { desa }\end{array}$ & 74.628 .800 & 73.128 .800 & 97.99 \\
\hline & & & $\begin{array}{l}\text { Pelatihan Aparatur } \\
\text { Pemerintah Desa } \\
\text { Bidang PKD }\end{array}$ & $\begin{array}{l}\text { Tersedianya } \\
\text { Aparatur } \\
\text { Pemerintah } \\
\text { Desa Dalam } \\
\text { Bidang PKD } \\
\end{array}$ & $\begin{array}{r}167 \\
\text { desa }\end{array}$ & 10.000 .000 & 9.500 .000 & 95 \\
\hline & & & $\begin{array}{l}\text { Pelatihan Aparatur } \\
\text { Pemerintah Desa } \\
\text { Dalam Bidang } \\
\text { Manajemen } \\
\text { Pemerintahan Desa }\end{array}$ & $\begin{array}{c}\text { Tersedianya } \\
\text { Aparatur } \\
\text { Pemerintah } \\
\text { Desa Dalam } \\
\text { Bidang } \\
\text { Manajemen } \\
\text { Pemerintahan } \\
\text { Desa }\end{array}$ & & 5.000 .000 & 4.550 .000 & 91 \\
\hline
\end{tabular}

Sumber: LAKIP Dinas Pemberdayaan Masyarakat dan Desa Kab. Minahasa Selatan

\subsection{Pembahasan}

Analisis Laporan Akuntabilitas Kinerja Pada Dinas Pemberdayaan Masyarakat dan Desa Kabupaten Minahasa Selatan Berdasarkan Perspektif Balanced Scorecard (BSC). Perspektif Balanced Scorecard yang di pakai dalam menganalisis Laporan 
Akuntabilitas Kinerja pada Dinas Pemberdayaan Masyarakat dan Desa Kabupaten Minahasa Selatan berjumlah 4 Perspektif antara lain yaitu sebagai berikut:

1. Perspektif finansial

2. Perspektif customer and stakeholders

3. Perspektif internal business process

4. Perspektif employees and organization capacitys

Dimana yang akan di ukur dan di analisis pertama yaitu Perspektif finansial.

Perspektif Finansial. Kinerja keuangan merupakan komponen penting bagi suatu organisasi karena kinerja keuangan dapat menunjukakan apakah strategi yang dilakukan memberikan kontribusi atau tidak. Dalam organisasi sektor publik pemerintah dituntut untuk mampu menghasilkan kinerja keuangan daerah yang baik. Untuk menghasilkan kinerja keuangan yang baik setiap unit kerja pemerintahan diharapkan dapat mengurangi terjadinya pemborosan, kebocoran dan mendeteksi program-program yang dianggap tidak layak guna meningkatkan pelaksanaan akuntabilitas publik. Perspektif keuangan bisa disebut sebgai tujuan akhir dari semua perspektif. Dikatakan sebagai tujuan akhir karena apa yang diperoleh pada perspektif keuangan akan dipergunakan kembali untuk mendanai segala rencana kegiatan penunjang jalannya kegiatan DPMD Kabupaten Minahasa Selatan. Dapat dilihat dari Tabel 1 di atas menunjukan kinerja yang baik dimana realisasi anggaran untuk beberapa kegiatan dapat di realisasikan dengan sangat baik, ini ditunjukan lewat presentase angka realisasi pada Tabel 1 dimana rata-rata presentase adalah $90 \%$ yang dalam indeks capaian kinerja dikategorikan sanagat baik. Hanya saja ada beberapa kegiatan dari Dinas Pemberdayaan Desa dan Masyarakat yang tidak terealisasi sehingga kegiatan yang telah disusun di dalam LAKIP tidak berjalan sesuai dengan apa yang telah di susun di dalam RENSTRA DMPD Kabupaten Minahasa Selatan.

Perspektif Costumer and Stakeholders. Pengukuran kinerja berdasarkan perspektif Costumer and Stakeholder dimana yang di analisis dan di ukur disini adalah fasilitas pelayanan yang di lakukan olah DPMD sudahlah sangat baik ini terlihat dari fasilitas-fasilitas DPMD yang sangat baik serta pelayanannya terhadap masyarakat. Ini terbukti lewat observasi secara langsung yang saya lihat di DPMD, seperti pelayanan jasa surat menyurat yang sangat baik dan cepat kemudian daripada ini penyediaan jasa komunikasi, sumber daya air dan listrik. Kemudian daripada itu jika dilihat pada tabel 4.1 di atas bisa dilihat bahwa penyediaan fasilitas jasa seperti:

a. Pelayanan jasa administrasi keuangan

b. Penyediaan alat tulis kantor

c. Penyediaan jasa pemeliharaan dan perizinan kendaraan dinas/operasional dan BBM.

Sudah sangat baik karena terlaksana dengan lancar capaian kinerjanya pun berada di rata-rata 90\% yang dalam indeks capaian kinerja dikategorikan sangat baik, hanya saja untuk dua penyediaan fasilitas jasa seperti:

a. Penyediaan barang cetakan dan penggandaan

b. Penyediaan jasa peralatan dan perlengkapan kantor

kurang terlaksana dengan baik karena bisa dilihat dari capaian kinerja dan realisasinya tidak mencapai 50\% yang dalam indeks capaian kinerja dikategorikan sedang.

Perspektif internal business process. Perspektif internal business process yang dimaksudkan disini adalah masyarakat desa yang dimana berhubungan dengan kegiatankegiatan yang dilaksanakan bersangkutan dengan pengembangan desa dan masyarakat seperti berikut:
a. Pemberdayaan Lembaga dan Organisasi Masyarakat Desa
b. Penyelenggaraan Pendidikan dan Pelatihan Tenaga Teknis dan Masyarakat
c. Penyelenggaraan Dimensi Informasi bagi Masyarakat
d. Pembinaan Kelompok Masyarakat Pembangunan Desa 
Dapat dilihat pada tabel 4.1 diatas dimana kegiatan-kegiatan yang dilaksanakan kepada masyarakat sudah sesuai dan sejalan dengan apa yang telah disusun dalam RENSTRA DPMD, sehingga apa yang telah dilaksanakan telah tepat sasaran dan realisasinya berada di atas rata-rata $85 \%$ yang dalam indeks kinerja dikategorikan baik. Sehingga kinerja yang dilakukan oleh DPMD pun sudah sangat baik. Tetapi adapun kegiatan yang di ukur melalui perspektif internal business process pendekatan balanced scorecard yang tidak terealisasi seperti Pelatihan Keterampilan Manajemen Badan Usaha Milik Desa

Perspektif Employee and Organization Capacity. Perspektif Employee and Organization Capacity yang dilihat disini adalah kegiatan-kegiatan yang berhubungan dengan pengembangan dan pelatihan aparatur desa, yang dapat dilihat pada tabel 4.1 diatas bahwa terdapat beberapa kegiatan-kegiatan yang berhubungan dengan pengembangan dan pelatihan aparatur desa yaitu sebagai berikut:

a. Pelatihan Aparatur Pemerintah Desa Dalam Bidang Pengelolaan Keuangan Daerah

b. Pelatihan Aparatur Pemerintah Desa Dalam Bidang Manajemen Pemerintahan Desa

c. Monitoring, Evaluasi dan Pelaporan

d. Pemilihan Hukum Tua / Pembekalan-Pembekalan Panitia dan Pelantikan Hukum Tua

Dari capaian kinerja kegiatan-kegiatan diatas dapat dilihat bahwa semua kegiatannya terlaksana dengan tepat sasaran sehingga capaian dan kinerja pemerintah DPMD Kabupaten Minahasa Selatan berada di atas rata-rata 95\% yang dalam indeks capaian kinerja dikategorikan sangat baik.

\section{KESIMPULAN DAN SARAN}

\subsection{Kesimpulan}

Dari hasil penelitian, maka dapat ditarik kesimpulan yaitu sebagai berikut:

1. Dari perspektif finansial bisa dilihat bahwa kinerja yang baik dimana realisasi anggaran untuk beberapa kegiatan dapat di realisasikan dengan sangat baik, ini ditunjukan lewat presentase angka realisasi dimana rata-rata presentase adalah 90\%, hanya saja ada beberapa kegiatan dari Dinas Pemberdayaan Desa dan Masyarakat yang tidak terealisasi sehingga kegiatan yang telah disusun di dalam LAKIP tidak berjalan sesuai dengan apa yang telah di susun di dalam RENSTRA DPMD Kabupaten Minahasa Selatan.

2. Dari perspektif customers and stakeholders fasilitas pelayanan yang di lakukan olah DPMD sudahlah sangat baik ini terlihat dari fasilitas-fasilitas DPMD yang sangat baik serta pelayanannya terhadap masyarakat. Ini terbukti lewat observasi secara langsung yang saya lihat di DPMD, seperti pelayanan jasa surat menyurat yang sangat baik dan cepat kemudian daripada ini penyediaan jasa komunikasi, sumber daya air dan listrik. Hanya saja ada beberapa kegiatan yang realisasinya tidak mencapai 50\%.

3. Dari perspektif internal bussines process yaitu kegiatan-kegiatan yang bersangkutan dengan pengembangan desa dan masyarakat sudah sesuai dan sejalan dengan apa yang telah disusun dalam RENSTRA DPMD, sehingga apa yang telah dilaksanakan telah tepat sasaran dan realisasinya berada di atas rata-rata $95 \%$ yang dalam indeks capaian kinerja dikategorikan sangat baik. Tetapi ada kegiatan yang tidak terealisasi

4. Dari perspektif Employee and Organization Capacity kegiatannya terealisasi dan terlaksana dengan tepat sasaran sehingga capaian dan kinerja pemerintah DPMD Kabupaten Minahasa Selatan sudah sangat baik. Ini terbukti lewat LAKIP capaian realisasi kinerja DPMD Kabupaten Minahasa Selatan yang berada diatas rata-rata 95\% yang dalam indeks capaian kinerja dikategorikan sangat baik.

\subsection{Saran}

Dari hasil pembahasan, maka penulis memberikan saran sebagai berikut :

1. Capaian Kinerja yang sudah baik dan telah di laksanakan capai oleh DPMD Kabupaten Minahasa Selatan perlu di pertahankan dan di kembangkan lagi. 
2. Perlu diperhatikan lagi terhadap kegiatan-kegiatan yang tidak terlaksana sehingga bisa diperbaiki dan ditingkatkan

3. Untuk realisasi fisik dari laporan kinerja DPMD Kabupaten Minahasa Selatan yang tidak mencapai $80 \%$ perlu di perhatikan dan ditingkat baik dari realisasi anggarannya maupun realisasi fisiknya.

\section{DAFTAR PUSTAKA}

Fairus. T. M dan Andri. S (2013) Perencanaan Kinerja Tahunan Melalui Penilaian Evaluasi Lakip. Jurnal Kebijakan Publik.

Halim, Abdul \& Kusufi M Syam 2014. Akuntansi Sektor Publik.Edisi 2.Salemba Empat. Jakarta

Huda. M dan Riharjo. I. B (2013) Analisis Pelaporan Kinerja Pada Dinas Kebudayaan Dan Pariwisata Provinsi Jawa Timur. Jurnal Ilmu \& Riset Akuntansi.

Kaplan dan Norton (2011). The Balanced Scorecard Translating Strategy Into Action. Massachusetts : Harvard Bussiness School Press.

Kuncoro, M. (2011) Metode Riset Untuk Bisnis dan Ekonomi Bagaimana Meneliti dan Menulis Tesis?, Edisi 3, Jakarta: Erlangga

LAKIP Dinas Pemberdayaan Masyarakat dan Desa Kab. Minahasa Selatan.

Lembaga Administrasi Negara dan Badan Pengawas Keuangan dan Pembangunan. (2000) Akuntabilitas dan Good Governance. Jakarta: LAN dan BPKP.

Mardiasmo (2011). Akuntansi Sektor Publik. Yogyakarta.Penerbit: Andi.

Santoso. S (2013) Analisis Laporan Akuntabilitas Kinerja Pada Dinas Kebudayaan Dan Pariwisata Provinsi Sulawesi Utara. Jurnal EMBA.

Sugiyono (2014) Metode Penelitian Kuantitatif, Kualitatif dan R\&D. Edisi ke 21. Bandung: Penerbit Alfabeta.

Sujarweni. V. W (2015). Akuntansi Sektor Publik. Yogyakarta : Pustaka Baru Press.

Thomas. S (2013). Akuntansi Intermediate. Jilid 1. Yogyakarta: Graha Ilmu.

Wild, John J., Ken. W. Shaw., dan Barbara. C (2014). Financial Accounting Information For Decisions is A Asian Adaption Of Fundamental Accounting. $20^{\text {th }}$ Edition. Mc Gra Hill Aducation (Asia). Singapore. 